\title{
Homofobia e homofobia interiorizada:
} produções subjetivas de controle heteronormativo?

\section{Homophobia and internalized homophobia: subjective productions of heteronormative control?}

\author{
Márcio Alessandro Neman do Nascimento \\ Universidade Estadual de Londrina \\ marcioneman@yahoo.com.br
}

\begin{abstract}
Resumen
O artigo problematizará, teoricamente, algumas questões emblemáticas que circunscrevem as homossexualidades na história, partindo de um posicionamento teórico-metodológico marcado pelos estudos culturais e de gênero realizados por autores pós-estruturalistas. $\mathrm{Na}$ atualidade, há muitos avanços e conquistas, no âmbito sócio-político, relacionadas à diversidade sexual. Entretanto, essa mesma visibilidade tem produzido disparadores para práticas sociais violentas demonstradas em crimes e discursos de ódio, intolerância e interdições veladas contra homossexuais. Assim, pretende-se apresentar a construção social da homofobia $e$, subseqüentemente, da homofobia interiorizada, uma vez que seus pilares formadores se sustentam por processos de subjetivação heteronormativa pulverizados em contextos sociais cotidianos.
\end{abstract}

Palabras clave: Homossexualidade; Homofobia; Gênero; Psicologia

\section{Abstract}

The article will theoretically problematize some emblematic issues that circumscribe homosexualities along history, starting from a theoretical-methodological position marked by cultural and gender studies by poststructuralist authors. At the present time, there are many progresses and conquests in the sociopolitical field related to the sexual diversity. However, such notoriety has produced triggers for violent social practices which are demonstrated in crimes and hate discourses, intolerance and veiled interdictions against homosexuals. Therefore, this article intends to demonstrate the social construction of homophobia and, subsequently, the construction of internalized homophobia, since its established pillars are sustained by processes of heteronormative subjectivation powdered in daily social contexts.

Na contemporaneidade, Castells (1999) problematiza que a sociedade vive processos contínuos de transformações desenfreadas e intensas, impulsionadas por avanços biotecnológicos, informativos e virtuais, nas amplas esferas sociais. Essas mudanças aceleradas produzem condições favoráveis para a reflexão acerca de novos modos de subjetivação, demonstrados em práticas sociais recorrentes e marcados em estilos de vida, mundo do trabalho, relações de sociabilidade, entre outros. 
Ainda, salienta-se também a propagação dos discursos dos Direitos Humanos, que pressupõem o Homem enquanto sujeito de direitos, produto e produtor dos acontecimentos sócio-histórico-culturais e políticos que influenciaram/influenciam todo o processo emancipatório ocidental, no qual se inclui, de maneira pungente, os direitos sexuais e reprodutivos. Esses direitos constituem-se na promoção, proteção e garantia das diversas expressões das sexualidades singulares e em sua legitimidade, bem como na apresentação de suas corporeidades e produções singulares de vida em sociedade, de maneira que Ihes tragam bem-estar e não infrinjam eticamente nenhuma outra pessoa ou os próprios sujeitos das sexualidades. Para tanto, buscou-se realizar interfaces com distintos saberes acadêmicos e populares, órgãos governamentais (saúde, assistência social, cultura, entre outros) bem como os órgãos dos poderes legislativo, executivo e judiciário.

Todavia, Spencer (1999) e Costa (1995) indicam que experiências homoeróticas estão presentes em diferentes épocas e civilizações do mundo ocidental, desde a exaltação greco-romana de juventude, virilidade e beleza, passando pelas representações subversivas encontradas na literatura de Sade no século XIX. Já nos séculos XX e XXI, pode-se citar as produções de artistas como, por exemplo, Tom of Finland e, mais recentemente, as inúmeras produções disponíveis nos cinemas e na internet.

No entanto, embora muito se discurse sobre a cultura homoerótica, a criação do personagem homossexual, ou seja, o termo homossexual foi utilizado pela primeira vez na Alemanha somente em 1869, pelo escritor austro-húngaro, Karl Maria Kertbeny. Em seguida, Richard von Kraft-Ebing, sexólogo, utilizou este termo em 1887, na segunda edição de Psychopathia sexualis, mas, segundo Spencer (1999), a divulgação para o grande público se deu pelos pesquisadores Hirschfeld e Havelock Ellis.

É importante ressaltar que a gênese do termo homossexual é apontada por Mello (2005) como sendo a união do prefixo grego (homo $=$ igual) com a raiz latina (sexual) que estruturou o conceito homossexual. Inapropriadamente, alguns tomam homo por uma origem latina, atribuindo ao termo homossexualidade o sentido de sexo entre homens, o que implica uma equivocada supressão das mulheres do campo semântico originariamente grego.

De acordo com Katz (1996), após o surgimento do termo heterossexual na sociedade norte-americana, em 1892, cunhado por Krafft-Ebing, o referido termo passou a significar, no século XX, uma sexualidade relativa ao sexo oposto, desvinculada da reprodução, afastando-se do ideal reprodutivo vitoriano e conduzido na direção da norma erótica moderna do sexo diferente. A partir de então, ofereceu-se ao mundo moderno dois sexos diferenciados, um bom e normal (heterossexual) e outro, ruim, anormal e pervertido (homossexual). Essa dicotomia viria a dominar a visão do universo sexual, uma vez que a heterossexualidade passou progressivamente a ser vista como uma sensualidade normal relativa ao sexo oposto, tornando-se uma premissa cultural dominante e consagrada.

O dimorfismo fisiológico dos sexos (anátomo-biológico) teve grande impacto nos processos de subjetivação, no que diz respeito, às mudanças no trabalho, papéis sociais, no poder exercido sobre as mulheres e nos ideais de feminilidade e masculinidade, ou seja, se efetivou em práticas discursivas baseadas no machismo (domínio masculino), heterocentrismo (elege a heterossexualidade como centro) e na heteronormatividade (norma da heterossexualidade compulsória - onde se presume que todas as pessoas são heterossexuais).

Entretanto, é fato que a percepção sobre as homossexualidades variou ao longo da história e a sua aceitação, segundo Weeks (1999), é recorrente, de acordo com a maneira de cada cultura manifestar 
suas crenças, tabus, preconceitos, produções científicas e artísticas, leis, costumes e legitimação dos Direitos Humanos. Mais recentemente, desde o "Levante de Stonewall", em 1969, até os dias atuais, a concepção do ser/estar homossexual e todos os fenômenos em seu entorno ampliaram consideravelmente suas inserções, seja no campo da vivência das afetividades, criação de estilos singulares de vida e (re)invenção das conjugalidades e parentalidades, entre muitas outras produções que não passam somente por interdições das práticas homoeróticas, embora ainda a homofobia seja destacada, mais fortemente, nas experiências dessas pessoas.

De acordo com Mott \& Cerqueira (2001) e Leony (2006), a homofobia pode ser compreendida como um ódio explícito, persistente e generalizado, que se expressa por práticas sociais violentas. Pode se apresentar tanto com agressões verbais enquadradas nas tipificações penais contra a honra quanto com atos extremos de violência física sendo, geralmente, evidenciados nos crimes com requinte de crueldade, que culminam em homicídios hediondos. Ainda, indicam que essas práticas são caracterizadas por elevado número de golpes desferidos por armas brancas ou disparos deflagrados, geralmente conjugados com o uso de múltiplos instrumentos de tortura prévia à execução.

Em Borrilo (2003), é indicada a complementação de que a homofobia pode ser caracterizada como um medo das homossexualidades e o desprezo pelos gays e lésbicas, ou para aqueles que presumem em sê-los. Porém, não pode ser resumida apenas em uma forma específica de violência, seja ela uma recusa irracional ou de ódio declarado, pois, como considera Nascimento (2007), normalmente pode estar condicionada a outras estigmatizações somativas advindas das categorias de raça/etnia, cor de pele, classe social e econômica, geração, identidade de gênero, status social e cultural, regionalismo, estética corporal entre outros.

De modo geral, ainda que as sanções ou práticas sociais violentas contra pessoas que são identificadas como homossexuais seja antiga, o termo homofobia foi empregado pela primeira vez em 1971, mas apareceu nos dicionários de língua francesa em meados de 1990, onde é definido como a rejeição das homossexualidades, a hostilização sistemática à consideração aos homossexuais. Junto à xenofobia, o racismo ou anti-semitismo, a homofobia é uma manifestação arbitrária que consiste em designar o outro como inferior ou anormal, ou seja, posicionando o outro como bizarro e estranho e não merecedor de sua participação cidadã em âmbitos públicos.

Partindo do exposto acima, Borillo (2003), problematiza que a homofobia, como processo exterminatório, não se limita a constatar uma diferença, pois ela também interpreta e tira suas conclusões materiais. Neste sentido, antigamente o homossexual era apontado e culpado do pecado de sodomia, sua condenação moral aparecia como necessária e a purificação pelo fogo da inquisição era a conseqüência lógica. Equivalente a um ato criminoso, era consagrado, nas sentenças brandas, ao ostracismo e, nos piores casos, à pena capital, como ainda continua sendo o caso em alguns países. Consideradas posteriormente como doença, as homossexualidades foram objetos da observação médica e submetidas às terapias coordenadas pelas ciências, entre elas destacando-se o eletro-choque, método utilizado no Ocidente até os anos 1960.

De acordo com Castañeda (1999), os países latinos, onde se inclui o Brasil, constituem como um dos povos mais homofóbicos do ocidente, devido à sua sociedade pautada no modelo patriarcal, machista e cristão. Segundo Parker (1991; 2002), o Brasil desponta como um dos mais importantes campos de pesquisa, no que tange às amplas e distintas expressões das sexualidades, demonstradas nas 
corporalidades, nas práticas afetivo-sexuais distintas e produtoras de rupturas nas bordas das identidades cristalizadas; porém, também considera que essa visão erotizada do povo brasileiro não pode deixar velada as práticas sociais violentas contra as declarações explícitas da pluralidade deste povo.

Na América Latina, no que tange às punições, ainda na Guiana, apenas a prática homossexual masculina é punida com possibilidade de prisão perpétua. No Brasil, embora tal discussão esteja em pauta, nas forças armadas a prática homossexual ainda é crime passível de prisão, seguida de expulsão da corporação. No que tange à união civil entre pessoas do mesmo sexo biológico, apenas países como a Argentina (restrito à cidade de Buenos Aires e à Província de Rio Negro), Guiana Francesa (PACS), Ilhas Malvinas e, em 2007, o México, autorizaram esse procedimento. Já em relação à criminalização da homofobia, no Brasil, o movimento social LGBT (Lésbicas, Gays, Bissexuais, Travestis e Transexuais) busca apoio para aprovação do Projeto de Lei da Câmara n 122/2006, que está em tramitação na Câmara dos Senadores, todavia, com grande resistência e ataques da bancada de fundamentalistas religiosos para que sua aprovação não seja efetivada.

Embora descrições históricas indiquem que, desde a Grécia Antiga, sanções às práticas homoeróticas são recorrentes, a formação do Estado homofóbico é entendida como consolidada apenas nos séculos XIII-XIV, na Idade Média - período das trevas - com o crescente avanço do cristianismo e do capitalismo, onde a Igreja encarregou-se de punir as pessoas acusadas de sodomia (Foucault, 2003; Spencer, 1999; Richards, 1993). As práticas sexuais entre homens eram condenadas, assim como toda prática que não tinha por finalidade a procriação (masturbação, bestialidade, coito anal) era dita como anti-natural e um afronto aos dogmas cristãos, de acordo com os manuais penitenciais e guias de confessores. Segundo Richards (1993), com a criação da Inquisição - Quarto Concílio Lateranense de 1215 - os tribunais da Igreja e do direito canônico iniciaram desenfreadas investigações aos pecadores e hereges (bruxaria/satanismo) e aos criminosos, perante o Estado e à moral familiar, indivíduos os quais eram apontados como promíscuos e libertinos.

Na contemporaneidade, segundo dados de Mott \& Cerqueira (2001), vinculados na imprensa brasileira (temporalmente, dados mais recentes no Brasil) a cada três dias, um crime de ódio contra a população LGBT é registrado. Contudo esses dados são incompletos, uma vez que muitos desses assassinatos nem sempre são notificados pelo poder público, sendo que os dados são agrupados por denúncias de organizações não-governamentais, familiares e amigos das vítimas, buscas na mídia, entre outras fontes informais.

Sobre o fato supracitado, Leony (2006) informa que as notícias referentes às estatísticas de crimes homofóbicos perpetrados, bem como o monitoramento e a avaliação das ações programáticas no âmbito da segurança pública nem sempre são disponibilizados de maneira organizada e sistematizada, fator que dificulta o acompanhamento e a avaliação da gestão política dos delitos de ódio a serem combatidos por esses órgãos gestores e, assim, investe que a contagem desses crimes deve ser bem maior.

Ainda, os trabalhos de Silva (1993), Mott \& Cerqueira (2001), Spagnol (2001), Borrilo (2003), Peres (2005), Leony (2006), Nascimento (2007), Pocahy (2007), Rios (2007), entre outros, refletem que, pensar o conceito homofobia, imediatamente, acarreta evocar cenas assustadoras e desumanas contra grupos não-heterossexuais (considerados perigosos por ameaçarem os papéis definidos de macho/fêmea nas funções vitais de manutenção, subsistência e segurança política e social), além de mencionarem o lado 
obscuro e encoberto de práticas sociais violentas e intolerantes, de cunho homofóbico, presentes na sociedade brasileira contemporânea.

Os mesmos autores, de modo geral, em seus trabalhos de cunho político, denunciam as hierarquizações e relações de poder que interditam o pluralismo das diferentes sexualidades em interface com outras expressões sócio-culturais, construídas ao longo da história e ainda vigentes no contexto atual de um país democrático, laico e que tem significativos avanços no campo dos Direitos Humanos. Acusam não só as situações extremas das práticas sociais violentas que resultam em óbito, mas também as práticas cotidianas e as manifestações de desprezo velado, entretanto, poderosas. Estas práticas sutis que ocorrem nos ambientes institucionais ou nas esquinas, segundo Silva (1993) e Nascimento (2007), podem ser um sorriso no canto esquerdo da boca, uma piada, um gesto, uma interdição, uma negação, uma maneira de dificultar uma ação do outro, enfim, uma atuação que legitima a consente tortura e sofrimento psíquico de homossexuais e, indiretamente, apóia o assassinato dessas pessoas.

De modo complementar, Welzer-Lang (2001) analisa que a homofobia cristaliza a possibilidade de transitoriedade entre os gêneros, sendo compreendida como discriminação aos sujeitos que Ihe fossem atribuídas adjetivos (bons ou ruins) referentes aos gêneros, engessando qualquer possibilidade de avançar as fronteiras bem demarcadas do feminino e masculino. Assim, estudar a homofobia implica em entender a lógica da dominação masculina, pois:

O paradigma naturalista da dominação masculina divide homens e mulheres em grupos hierárquicos, dá privilégios aos homens à custa das mulheres. Em relação aos homens tentados, por diferentes razões, de não reproduzir esta divisão (ou, o que é pior, de recusá-la para si próprios), a dominação masculina produz homofobia para que, com ameaças, os homens se calquem sobre os esquemas ditos normais da virilidade[...] (Welzer-Lang, 2001, p. 465)

Dessa maneira, para o autor, a homofobia pode ser referenciada como uma relação transversal e relacional do domínio masculino, tendo, em seu suporte, pilares constituídos do machismo, (heteros)sexismo, heterocentrismo, heteronormatividade e do viriarcado (que remonta a idéia do homem dominante e viril que também está submetido às hierarquias masculinas). Sobre o heterossexismo é indicado como:

[...] a discriminação e opressão baseadas em uma distinção feita a propósito da orientação sexual. O heterossexismo é a promoção incessante, pelas instituições e/ou indivíduos, da superioridade da heterossexualidade e da subordinação simulada da homossexualidade. O heterossexismo toma como dado que todo mundo é heterossexual. (Welzer-Lang, 2001, p. 467-468).

O heterocentrismo, com sua idéia de marginalizar as sexualidades que fogem à matriz heterossexual, adota categorias para estabelecer hierarquização e relações de poder que "distinguem os dominantes, que são os homens ativos, penetrantes, e os outros, aquelas e aqueles que são penetradas/os, logo dominadas/os [...]" (Welzer-Lang, 2001, p. 468). Assim, a homofobia que tem como um de seus pilares o heterocentrismo, desvaloriza e menospreza todas aquelas pessoas que são identificadas ou assumem configurações sexuais e de gênero ditas como não-naturais, ou seja, fora do paradigma heterossexista. 
Contudo, essa produção heteronormativa em pensar as sexualidades era dada desde a antiguidade, na existência da vida ética na Grécia Clássica. Foucault (2002; 2003) revela que naquela época era proposto que o homem grego tivesse como referencial ser forte o suficiente para se libertar das dominações do mundo, ou seja, que promovesse o governo de si mesmo e controlasse seus desejos e prazeres mediante a ameaça de exclusão do mundo social dos homens cidadãos. O amor grego, como erroneamente é interpretado pelo imaginário e por alguns autores, não era tão livre de regras sociais, uma vez que possuía uma política dos gêneros muito bem demarcada.

Ainda, sobre as ameaças da delimitação entre o feminino e masculino e o conseqüente afastamento do componente viril, Foucault (2003) e Vrissimtzis (2002) apontam que, na Grécia Antiga, o controle das práticas sociais era dado não por um medo de contrariar a natureza biológica, mas sim de se contrapor ao papel descrito ao homem enquanto cidadão. Pois, de um lado se sobressaia os homens adultos e livres - com vida pública, status social, ativos em todos os sentidos (sexual e político); do outro lado estavam postos os sujeitos passivos - mulheres, crianças, rapazes e escravos, que eram desprovidos de participação na vida pública e do título de cidadão - condição que incluía o desconhecimento sobre a dinâmica da vida social, das funções do Estado e dos valores éticos e morais. Neste contexto da Antiguidade, começa a surgir, por volta do século VI a.C. e durante até o século IV a.C. - a pederastia.

A pederastia, segundo Vrissimtzis (2002, p. 101), "denotava a afeição espiritual de um homem adulto por um garoto e, por conseguinte, não possuía significado obsceno". O que tornava a pederastia legítima e aceitável na Grécia, (Foucault, 2003; Vrissimtzis, 2002), era o fato de que ela era vista como uma instituição pedagógica atribuída a um ritual de iniciação no qual um homem adulto e de classe social superior (erástes - amante) que terminou sua formação cidadã (papel social, moral e condição sexualmente ativa) transmitiria seus conhecimentos e experiências a um jovem (erómenos - amado). Este jovem, logo precisaria desses aprendizados para ingressar na pólis e ter o status de cidadão, uma vez que a escola não possibilitava estes aprendizados. Na atualidade, a pederastia foi condicionada à idéia do senso comum de abuso sexual por homossexuais, entendida como crime de pedofilia.

Ainda sobre as práticas homoeróticas masculinas, Foucault (2003) indica que o Estado não tolerava as práticas de penetração entre dois homens, punindo-as severamente, com leis específicas de controle. Portanto, não convinha ao erómenos agir passivamente, no sentido de ceder e se deixar dominar pelo erástes; deveria agir como se fosse um contrato que beneficiasse a sua vida pública, demonstrando sentimentos de admiração, afeição, respeito e amizade para com seu tutor; devia evitar a entrega aos prazeres da carne de modo passivo, pois tal passividade era associada ao papel inferiorizado da mulher.

Na Roma Antiga, Veyne (1986), as questões relacionadas às sexualidades não eram diferentes da organização social grega. A posição de passividade (que se contrapunha ao de atividade) era condenada, pois denotava a falta de virilidade - ser macho - que despontaria como uma ameaça à segurança e interesses de Roma. Este Estado treinava seus homens para serem combatentes, guerreiros, para que defendessem sua pátria bravamente e acreditavam que só um homem viril seria capaz de tal feito. Assim como acontecia na Grécia, a passividade maculava a condição de cidadania e reconhecimento social enquanto sujeito público.

Complementando essa rigidez normativa relacionada às sexualidades, aos desejos, às práticas e aos gêneros, Borrilo (2000) reflexiona que a homofobia, da mesma forma que o sexismo e o machismo, hierarquiza e confere uma supremacia dos homens sobre as mulheres, apresentando-se como um 
componente eficiente e potente para legitimar o binário sexual e para ordenar as diferenças entre homossexuais e heterossexuais.

Nesta lógica do binarismo sexual, da dominação masculina e dos pressupostos que sugerem um mundo heterossexista, Louro (2003) expõe que a população LGBT poderia ser compreendia como ex-cêntrica (fora do heterocentrismo), uma vez que esse grupo não-heterossexual seja considerado seres abjetos, (Butler, 1999; 2003), justamente porque demonstram um descontentamento ao gênero do qual arbitrariamente pertencem seus sexos biológicos. A cultura heterossexual dominante passa, então, a considerar seres abjetos essas pessoas entendidas como seres bizarros, desprezíveis, desviantes, anormais, marginais, subumanos, sub-cidadãos que devem ocupar e existir apenas nos lugares inabitáveis e de sub-cultura, ou não existirem. Assim, são seres que ameaçam a ordem heterossexual, seres que deveriam habitar tão somente o espaço imaginário e/ou mitológico ou, ainda, ocuparem apenas territórios marginais como, por exemplo, lugares autorizados de guetificação, como demonstrado por Nascimento (2007).

A partir do exposto acima, em uma ordem epistemológica, Borrillo (2003) propõe não buscar compreender a origem e funcionamento das homossexualidades, mas sim analisar como se processa esta hostilidade desencadeada diante de tudo que se refere a esta temática.

Neste sentido político, a questão extrapola as homossexualidades e adentra a problemática da homofobia, pois este assunto não se restringe a um grupo, raça, credo religioso ou à origem étnica específica, mas trata-se da construção política do cidadão sexuado e que, por conseqüência, pode assumir graus diferenciados em suas manifestações, quando associadas às categorias citadas em processos somativos de estigmatização.

Assim como é sabido que travestis pertencem a um grupo bastante exposto à violência, (Peres, 2005), os homossexuais efeminados, as lésbicas e os gays mais assumidos também fazem parte de um grupo de pessoas mais vulneráveis às expressões de práticas sociais violentas. Mas não se trata apenas de uma violência física, patrimonial ou psicológica a que esses grupos de pessoas, vistas como abjetas, estão mais vulneráveis, mas, também, no que tange à saúde física, em especial, à infecção pelo vírus HIV, como encontrado nos estudos de Terto-Jr (2002).

Seguindo um referencial genealógico foucaultiano, compreende-se que esses acontecimentos históricos de ordem disciplinadora foram e são estratégias não localizáveis de relações de forças dito como dispositivo da sexualidade, (Foucault, 2005). Dessa maneira, esse dispositivo por meio de práticas discursivas extrapola as instâncias jurídicas do poder (Estado e Lei) e atuam com mecanismos e articulações próprias de sujeição, controle e normatização sobre a vontade do sujeito, desta forma, atuando sobre a vida e a morte dos assujeitados a essa estratégia política do poder que produz subjetividades.

A subjetividade, trazida por Guattari \& Rolnik (1986), pode ser expressa a partir da inscrição das pessoas no mundo, sendo um fato social construído e mediado nas relações sociais e, também, engendrado por determinantes sociais, tais como determinantes históricas, políticas, religiosas, culturais, enfim, por diversos fatores heterogêneos. Em referência às sexualidades, esses fatores heterogêneos produzem subjetividades assujeitadas a heteronormatividade, bem como produzem processos de resistência, que buscam a emancipação e o respeito às diferenças. Nesse contexto surgem impasses como, por exemplo, os aspectos que atormentam os homofóbicos, causados pela tentativa do movimento LGBT em 
tirar a homossexualidade da esfera íntima e reivindicar publicamente sua equivalência à heterossexualidade.

Dentre as retóricas anti-homossexuais, na década de 50, potencializaram-se, além dos discursos fundamentalistas homofóbicos, os enunciados das ciências (psicologização e patologização) do desejo homossexual, corroborando para as desigualdades sociais, culturais e jurídicas das sexualidades.

Sobre as pessoas homofóbicas, Mello (2005, p. 193) analisa que estes "costumam ser conservadores, rígidos e favoráveis à manutenção dos papéis sexuais tradicionais", pois a homofobia está associada ao machismo, ao fundamentalismo religioso e, ainda, pode estar relacionada à misoginia. $\mathrm{O}$ mesmo autor aponta que a homofobia despertada no imaginário heterocêntrico dominante pode ser atribuída também aos desejos homoeróticos dados, consciente ou inconscientemente, nos próprios homofóbicos.

De maneira complementar, Castañeda (1999) problematiza que uma das funções fundamentais da homofobia diz respeito à negação de si próprio, de qualquer desejo homoerótico latente e que deve ser reprimido; em outras palavras, seria o receio de que a homossexualidade do outro possa despertar algo oculto em si, o que tornaria o homofóbico uma pessoa doente, pecadora e imoral, tanto quanto aquele que o mesmo despreza.

Já em relação à psicologização e à patologização do homoerotismo, é fato que a homossexualidade foi retirada da classificação de desordem mental pela Associação de Psiquiatria Americana, em 1973. No Brasil, o Conselho Federal de Medicina retirou a homossexualidade da lista dos desvios sexuais, em 1985. A Assembléia Geral da Organização Mundial da Saúde (OMS) aprovou, em 17 de maio de 1990, a retirada do código 302.0 (Homossexualidade) da Classificação Internacional de Doenças, apontando que a homossexualidade não constitui doença, nem distúrbio, nem perversão, sendo que essa prerrogativa só foi vigente entre os países-membro das Nações Unidas, em 1994. Entretanto, para um segmento específico da população LGBT, a saber, as pessoas transexuais, o não-conformismo ao gênero continua a ser uma patologia, uma vez que o DSM IV de 1994 inclui a categoria desordem de identidade do gênero como uma doença mental.

No Brasil, ainda sobre documentos relacionados à ética profissional, a resolução $n^{\circ} 001 / 99$, de 22 de março de 1999, do Conselho Federal de Psicologia Brasileiro (CFP), declara, em seu artigo $3^{\circ}$, o veto ao profissional que favorecesse a patologização a aspectos referentes ao homoerotismo, bem como aos tratamentos coercitivos para uma possível reversão das homossexualidades. Essa preocupação ética com as práticas homofóbicas, dentro da psicologia, deu-se em decorrência da grande procura de homossexuais por especialistas, devido ao sofrimento psíquico causado pela interiorização da homofobia. Estes, por fim, eram assolados em clínicas, devido a crenças pessoais e morais de profissionais que depunham contra a diversidade sexual.

A homofobia interiorizada analisada em nível individual, Chauvin (2003), assume ações nefastas àqueles homossexuais que se sujeitem às regras sociais heteronormativas, de modo que interfira em suas experiências existenciais, momentos de angústia e mal-estar e, consequentemente, em suas autoestimas. De modo geral, antes mesmo do coming out (sair do armário) de alguns, muitos já acompanharam de perto os sentimentos permanentes e cruéis de vergonha e culpa que acompanham a descoberta ou a tentativa de aceitação de si mesmo e a consciência crescente de fazer parte de uma classe de sujeitos inapropriados perante a sociedade. Tais sentimentos potencializam as 
vulnerabilidades da população LGBT, sendo que a análise propriamente política da vergonha converge para a crítica da ordem social heterossexista.

A homofobia interiorizada, enquanto processo de opressão e vergonha de si, é um mecanismo poderoso, graças ao qual a ordem social nos contém e nos mantém sob o próprio aprisionamento, fazendo com que homossexuais se escondam e mantenham-se invisíveis, a fim de não serem identificados como pertencentes àquela categoria estigmatizada. O pressuposto da homofobia interiorizada é o de que nenhuma dominação pode se exercer por longo tempo, se ela não for, de uma ou outra maneira, interiorizada por aqueles que ela tem como proposta estratégica de assujeitar ou de inferiorizar. Através da vergonha, o poder da heterossexualidade (o qual faz uso da homofobia para exercer-se) se apóia sobre os sujeitos e, dessa forma, faz uma imposição e uma auto-imposição acerca dos sentimentos de ser ridículo e de ser inapropriado mediante a ordem hierárquica da sociedade heterossexista. Esses contextos tirânicos promovem produções subjetivas normatizadas que, pré-dispostas psicologicamente aos homossexuais, são reconhecidas como divisões instituídas e autoritariamente estruturadas e, assim, conferem à homofobia uma parcela do poder por vezes paradoxal que ela exerce sobre eles.

Outra produção negativa da homofobia interiorizada diz respeito à incorporação do desprezo que outros sujeitos dirigem aos homossexuais e que estes, em muitos casos, aceitam, pois se sentem culpados em não corresponder aos padrões heterossexuais idealizados. Tal mecanismo pode ser compreendido, então, como o medo de se assemelhar aos perfis mais estigmatizados das homossexualidades, alimentando a vergonha de si e também projetando, frequentemente, o ódio de si mesmo no outro, proporcionando sofrimento de ordem subjetiva, ou seja, nas vivências cotidianas, (Chauvin, 2003).

Em um panorama geral, a visão naturalizada e essencialista das pessoas homofóbicas sobre a relação sexo/gênero/desejo/práticas sexuais reduz a identidade de pessoas que diferem da categoria heterossexual como sendo uma condição marcada apenas pela classificação sexual, nas quais passam a ser vistas como provocações ambulantes que maculam a moral da vida social, estas promotoras das condições para que os homossexuais se sintam repulsivos quando em público e, assim, se tornem invisíveis, (Chauvin, 2003).

Castañeda (1999) revela que, além da vergonha expressa, existem outros aspectos relevantes que atuam em termos psíquicos, ou seja, de importância clínica, entre eles: o luto da heterossexualidade, os segredos que geram dificuldades em lidar com situações até mesmo corriqueiras para pessoas heterossexuais, assim como favorecem a ocorrência das diversas expressões da violência, como, por exemplo, a chantagem, o suicídio, a vulnerabilidades às DSTs e ao HIVIAIDS entre outros.

Dessa maneira, a autora supracitada indica que a maioria dos homossexuais, ainda na atualidade, carrega consigo uma imagem desvalorizada de si, um conflito existencial em relação à própria sexualidade. Esses conflitos, que são exteriores aos sujeitos, dizem respeito a uma não conformidade às regras e normas sociais e dobram-se para dentro do sujeito, trazendo-lhe a sensação de ser um conflito psíquico interno, gerando, portanto, culpa e frustração. Esta percepção distorcida sobre as homossexualidades (de si e dos outros), difundidas socialmente e interiorizadas pelos sujeitos ditos homossexuais, fazem com que os mesmos tracem um projeto de vida em desvantagem frente aos heterossexuais. Sobre essa afirmação ardilosa, Castañeda (1999), diz que esta sugestão de desvantagem é dada pela imposição de isolamento afetivo e social aos quais muitos homossexuais tiveram de se submeter durante a vida, principalmente quando residentes em cidades interioranas. 
Ainda sobre as delimitações impostas ao desenvolvimento social, profissional e de relacionamentos afetivos de grupos de não-heterossexuais, Castañeda (1999) adverte que estas condições não permitem que os homossexuais aprendam certas competências sociais e estilos de vida próprios da cultura heterossexual, ou seja, eles não compartilham certos campos afetivos e não possuem oportunidades de efetivarem, se desejarem, certas ocasiões cotidianas e marcantes em sociedade, como, por exemplo, namorar, flertar em público, casar, relacionar-se familiarmente, entre outras assimilações.

Todavia, a construção do processo identificatório de gays e lésbicas, tanto no plano pessoal quanto coletivo, atua de maneira a resistir ao abuso dos mecanismos de controle mencionados e a pensar em novos estilos de vida. Se existe a vergonha gay (homofobia interiorizada), o seu contrário diz respeito ao orgulho da diversidade sexual, difundidos nas Paradas de Orgulho LGBT de todo o mundo. Este orgulho se faz mediante uma (re)apropriação de estilos de vida e identidades não-hegemônicas, condição que reverteria o estigma em orgulho, tanto privado quanto público, reivindicando sua existência de modo a desbancar o discurso heterossexista.

Para tanto, Chauvin (2003) diz que o fato de a comunidade LGBT se mobilizar, além de alavancar mobilizações políticas, impulsiona a (des)construção de toda a rede de idéias que as atravessa e interioriza e, assim, engendra a vergonha e o ódio de si mesmo. Neste sentido, poderiam produzir uma rede de sustentabilidade para a possível emancipação psico-social e política, de maneira a construir condições que favorecem a cidadania, a inclusão social e a redução das desigualdades de gênero.

A ponto de concluir, é importante salientar que, enquanto sujeitos históricos, os seres humanos são constituídos subjetivamente por meio de diversas linhas normatizadoras e tantos outros feixes de resistência e de produções de singularidades que tecem as estilísticas de existência no mundo que, de um jeito ou outro, permeiam distintos e amplos modos de relacionar-se consigo mesmo e com os outros.

As produções de subjetividade normatizadora tentam demarcar intensamente identidades fixas e absolutas, definindo assim, práticas discursivas, papéis sociais a serem encenados, desejos e prazeres a serem controlados, corpos e práticas a serem regulados e disciplinados. Já outros delineamentos que atravessam os sujeitos subjetivamente e permitem resistência ao poder proporcionam linhas de fuga para a criação de práticas sociais na ordem do novo, excêntrico e intempestivo que, consequentemente, trazem instabilidade aos desejosos de normas e aos viciados de identidades, pois propõe rupturas ao paradigma do binarismo sexual colocado como certo e único.

Partindo dessas premissas, o discurso da homofobia se apropria da heteronormatividade como instrumento que produz corpos, sexos, gêneros, práticas sexuais entre outros, determina uma lógica inteligível que tenta definir o certo e o errado, o são e o patológico, o pecaminoso e o santificado e, subsequentemente, definindo padrões de condutas e desejos que realizam a manutenção aos modelos dados como normais.

Por fim, os estudos das homossexualidades não deveriam somente pensar sobre as condições avassaladoras da homofobia e homofobia interiorizada, mas também reflexionar e problematizar outras maneiras de busca de prazeres e existências, sociabilidades, afetos e amores. Em suma, as construções sociais e as expressões das homossexualidades poderiam ser compreendidas como produções singulares da ética da existência e, talvez assim, as práticas discursivas dos homossexuais não buscassem o status quo da heterossexualidade, mas (re)inventassem as possibilidades de estilos criativos de vida em sociedade. 


\section{Referências}

Borrillo, Daniel (2000). L'homophobie. Paris: Presses Universitaires de France.

Borrillo, Daniel (2003). Homophobie. In Frédéric Haboury (Ed.), Dictionnaire des cultures gays et lesbiennes (pp.255). Paris: Larousse.

Butler, Judith (1999). Corpos que pesam: sobre os limites discursivos do "sexo". In

Guacira Lopes Louro (Ed.), O Corpo Educado: pedagogias da sexualidade (pp. 153-172). Belo Horizonte: Autêntica.

Butler, Judith (2003). Problemas de gênero: feminismo e subversão da identidade. Rio de Janeiro: Civilização Brasileira.

Castañeda, Marina (1999). Comprendre l'homosexualité : Des clés, des conseils pour les homosexuels, leurs familles, leurs thérapeutes. (Collection Réponses) Paris : Editions Robert Laffont.

Castells, Manuel (1999). O poder da identidade. Gerhardt. São Paulo: Paz e Terra.

Chauvin, Sébastien (2003). Honte. In Louis-Georges Tin (Ed.), Dictionnaire de l'homophobie (pp. 222226). Paris: Presses Universitaires de France.

Costa, Jurandir Freire (1995). A face e o verso - estudos sobre o homoerotismo II. São Paulo: Ed. Escuta.

Foucault, Michel (2002). História da sexualidade 3: o cuidado de si ( $7^{\mathrm{a}}$ ed). Rio de Janeiro: Edições Graal.

Foucault, Michel (2003). História da sexualidade 2: o uso dos prazeres $\left(10^{\mathrm{a}} \mathrm{ed}\right)$. Rio de Janeiro: Edições Graal.

Foucault, Michel (2005). História da sexualidade 1: a vontade de saber (16 ${ }^{\mathrm{a}}$ ed). Rio de Janeiro: Edições Graal.

Guattari, Félix \& Rolnik, Suely (1986). Subjetividade e história. In Félix Guattari \& Suely Rolnik. Micropolítica: cartografias do desejo (pp. 25-126). Petrópolis: Vozes.

Katz, Jonathan Ned (1996). A invenção da heterossexualidade. Rio de Janeiro: Ediouro.

Leony, Mário de Carvalho (2006). Homofobia, controle social e política pública de atendimento. Aracaju: UFS. (Monografia apresentada ao programa de pós-graduação Lato Sensu em Gestão Estratégica em Segurança Pública da Universidade Federal de Sergipe).

Louro, Guacira Lopes (2003). Currículo, gênero e sexualidade: o "normal", o "diferente" e o "excêntrico". In Louro et al (Eds.). Corpo, gênero e sexualidade (pp. 41-52). Petrópolis: Vozes.

Mello, Luiz (2005). Novas famílias: conjugalidade homossexual no Brasil contemporâneo. Rio de Janeiro: Garamond. 
Mott, Luiz \& Cerqueira, Marcelo (2001). Causa mortis: homofobia (violação dos Direitos Humanos e assassinato de homossexuais no Brasil em 2000). Bahia: Grupo Gay da Bahia.

Nascimento, Márcio Alessandro Neman do (2007). Homossexualidades ehomossociabilidades: hierarquização e relações de poder entre homossexuais masculinos que freqüentam dispositivos de socialização de sexualidades GLBTTT. Assis/São Paulo: UNESP. (Dissertação apresentada ao programa de pós-graduação em psicologia da Faculdade de Ciências e Letras de Assis, Universidade Estadual Paulista "Júlio de Mesquita Filho" - UNESP).

Parker, Richard (1991). Corpos, prazeres e paixões: a cultura sexual no Brasil contemporâneo. São Paulo: BestSeller.

Parker, Richard (2002). Abaixo do Equador: culturas do desejo, homossexualidade masculina e comunidade gay no Brasil. Rio de Janeiro: Record.

Peres, Wiliam Siqueira (2005). Subjetividade das travestis brasileiras: davulnerabilidade da estigmatização à construção da cidadania. Rio de Janeiro: UERJ/Instituto de Medicina Social. (Tese apresentada ao programa de pós-graduação em Saúde Coletiva do Instituto de Medicina Social da Universidade do Estado do Rio de Janeiro - UERJ).

Pocahy, Fernando (2007). Um mundo de injúrias e outras violações. Reflexões sobre a violência heterossexista e homofóbica a partir da experiência do CRDH - Rompa o Silêncio. In Fernando Pocahy (Ed.), Rompendo o silêncio: homofobia e heterossexismo na sociedade contemporânea (pp. 10-26). Porto Alegre: Nuances.

Richards, Jeffrey (1993). Sexo, desvio e danação: as minorias na Idade Média. Rio de Janeiro: Jorge Zahar.

Rios, Roger Raupp (2007). O conceito de homofobia na perspectiva dos Direitos Humanos e no contexto dos estudos sobre preconceito e discriminação. In Fernando Pocahy (Ed.), Rompendo o silêncio: homofobia e heterossexismo na sociedade contemporânea (pp. 27-48). Porto Alegre: Nuances.

Silva, Hélio R. S. (1993). Travesti: a invenção do feminino. Rio de Janeiro: Relume-Dumará/ ISER.

Spagnol. Antônio Sérgio (2001). Desejo marginal: violência nas relações homossexuais. São Paulo: Arte \& Ciência.

Spencer, Colin (1999). Homossexualidade: uma história. Rio de Janeiro: Record.

Terto Junior, Veriano (2002). Homossexualidade e saúde: Desafios para a terceiradécada da epidemia de HIVIAIDS. In Horizontes Antropológicos 8(17), 147-158. Porto Alegre.

Veyne, Paul (1986). A homossexualidade em Roma. In Philippe Ariès y André Béjin, (Eds.), Sexualidades ocidentais: contribuições para a história e para a sociologia da sexualidade (pp.39-49). São Paulo: Brasiliense.

Vrissimtzis, Nikos A. (2002). Amor, sexo e casamento na Grécia Antiga. São Paulo: Odysseus. 
Weeks, Jeffrey (1999). O corpo e a Sexualidade. In Guacira Lopes Louro (Ed.), O Corpo Educado: pedagogias da sexualidade. (pp.35-82). Belo Horizonte: Autêntica.

Welzer-Lang, Daniel (2001). A Construção do masculino: dominação das mulheres e homofobia. Revista Estudos Femininos, 9(2), 460-482.

\section{Formato de citación}

Nascimento, Márcio Neman do (2010). Homofobia e homofobia interiorizada: produções subjetivas de controle heteronormativo?. Athenea Digital, 17, 227-239. Disponible en http://psicologiasocial.uab.es/athenea/index.php/atheneaDigital/article/view/662

Este texto está protegido por una licencia Creative Commons.
Usted es libre de copiar, distribuir y comunicar públicamente la obra bajo las siguientes condiciones:
Reconocimiento: Debe reconocer y citar al autor original.
No comercial. No puede utilizar esta obra para fines comerciales.
Sin obras derivadas. No se puede alterar, transformar, o generar una obra derivada a partir de esta obra.
Resumen de licencia - Texto completo de la licencia


